\title{
Monitoring the Impact of Environmental Manipulation on Peatland Surface by Simple Remote Sensing Indices
}

\author{
Anshu Rastogi ${ }^{1, *}$, Subhajit Bandopadhyay ${ }^{1}$, Marcin Stróżecki ${ }^{1}$, and Radosław Juszczak ${ }^{1}$ \\ ${ }^{1}$ Meteorology Department, Poznan University of Life Sciences, Piątkowska 94, 60-649 Poznań, Poland
}

\begin{abstract}
The behaviour of nature depends on the different components of climates. Among these, temperature and rainfall are two of the most important components which are known to change plant productivity. Peatlands are among the most valuable ecosystems on the Earth, which is due to its high biodiversity, huge soil carbon storage, and its sensitivity to different environmental factors. With the rapid growth in industrialization, the climate change is becoming a big concern. Therefore, this work is focused on the behaviour of Sphagnum peatland in Poland, subjected to environment manipulation. Here it has been shown how a simple reflectance based technique can be used to assess the impact of climate change on peatland. The experimental setup consists of four plots with two kind of manipulations (control, warming, reduced precipitation, and a combination of warming and reduced precipitation). Reflectance data were measured twice in August 2017 under a clear sky. Vegetation indices (VIs) such as Normalized Difference Vegetation Index (NDVI), Photochemical Reflectance Index (PRI), near-infrared reflectance of vegetation (NIRv), MERIS terrestrial chlorophyll index (MTCI), Green chlorophyll index (CIgreen), Simple Ration (SR), and Water Band Index (WBI) were calculated to trace the impact of environmental manipulation on the plant community. Leaf Area Index of vascular plants was also measured for the purpose to correlate it with different VIs. The observation predicts that the global warming of $1^{\circ} \mathrm{C}$ may cause a significant change in peatland behaviour which can be tracked and monitored by simple remote sensing indices.
\end{abstract}

\section{Introduction}

Several scientific surveys have shown that climate change is real, and is mainly caused by several anthropogenic activities [1,2]. Therefore, it is a need of the time to study the potential impact of current and forecasted future climate changes at different levels for different ecosystems. The peatlands are one of the most important ecosystems, as they contains around $40 \%$ of soil carbon even if it is estimated that the peatlands cover only around $3 \%$ of the terrestrial area [3]. Because of their big biodiversity, rich carbon content, and sensitivity to the environmental changes, peatlands have attracted a lot of attention of climate scientist [4-6]. The peat accumulation in peatlands depends on several biotic and abiotic factors; biotic factors include: the presence of vegetation and microorganism types, its physiological status, and stage of development [7], whereas abiotic factors include $\mathrm{pH}$, water table level, precipitation, temperature etc. [8-10]. The study by Dieleman et al. shows that the temperature change by $4^{\circ} \mathrm{C}$ and an elevated $\mathrm{CO}_{2}$ cause a shift in peatland plant community from Sphagnum to a graminoid-dominated vegetation [4]. An increase in temperature may lead to decrease in ground water level and enhance oxidative breakdown of the peat [11]. The increase in temperature may also kill microorganisms, impact plant physiology, alters nutrients level, and influence peat formation [5], whereas change in precipitation is also known to decrease water table level, plant physiology, nutrient level, and peat accumulation $[5,12]$. Thus, the precipitation and global temperature are important parameters which may change in future climatic condition and may influence the peatlands.

The information obtained through remote sensing has been proven to be useful in the estimation of growth, vigour, dynamics of the vegetation, and provide useful information about the impact of climate change [13]. The vegetation indices obtained through spectral remote sensing technique are used for rapid, efficient, and nondestructive observation of global vegetation [14]. The spectral reflectance under stress condition increases at visible and short-wave infrared, whereas reduces at near infrared band, thus the spectra obtained from stressed plants differs from the spectra obtained from healthy plants [15]. Different vegetation indices (VIs) are calculated by different combinations of visible and near infrared bands, which indicates different properties of earth vegetation characteristics. Therefore, the ecosystem or environment having a specific and complex feature needs to be analysed through combination of different VIs. In this work we have chosen indices such as, Normalized Difference Vegetation Index (NDVI), Photochemical Reflectance Index (PRI), near-infrared reflectance of vegetation (NIRv), MERIS terrestrial chlorophyll index (MTCI), Green chlorophyll index (CIgreen), Simple Ration (SR) and Water Band Index (WBI) for the purpose to find most suitable VIs to identify the impact of environmental manipulation on peatland vegetation. NDVI and SR were 
selected because they define canopy growth characteristic [16,17], whereas NIRv is selected because a recent study have indicated it to be a good proxy for plant fluorescence, thus more near to growth primary productivity [18]. MTCI and CIgreen were selected, as they are proxy for chlorophyll content [17], and WBI was selected for the evaluation of canopy water content in water saturated peatland ecosystem [19]. Leaf Area Index (LAI) of different experimental area was measured for the purpose to find a correlation between LAI and VIs, whereas chlorophyll content of different plants was measured to directly estimate total chlorophyll concentration of the manipulated plots. A relationship between different VIs, LAI, and Chlorophyll content is discussed for the purpose to better understand the impact of environmental manipulation on peatland.

\section{Material and method}

\subsection{Study area}

For this study the experimental site was selected because of its established setup for environmental manipulation experiment, which was established in 2014 under WETMAN project (a combined project of Poland and Norway). The experimental site is located in the Rzecin peatland $\left(52^{\circ} 45^{\prime} 43^{\prime \prime} \mathrm{N} 16^{\circ} 18^{\prime} 35^{\prime}\right.$ 'E, $54 \mathrm{~m}$ a.s.l.) area of western Poland [20-22]. The site consists of four treatments with three replication for each condition. The replicated plots are of square shape, with a size of $72 \times 72$ $\mathrm{cm}$. The treatment conditions are: control (C); simulated warming (W); warming and reduced precipitation (WRP); and reduced precipitation (RP).

Peat temperature was measured continuously in each of the twelve plots at $2 \mathrm{~cm}$ depth with T-107 thermistors (Campbell Sci. USA). Precipitation was measured with the four heated TPG-124-H24 rain gauges (ASTER, Poland) installed in the middle of the four treated sites, to have two sensors exposed to rain-manipulated and two to non-rain-manipulated conditions.

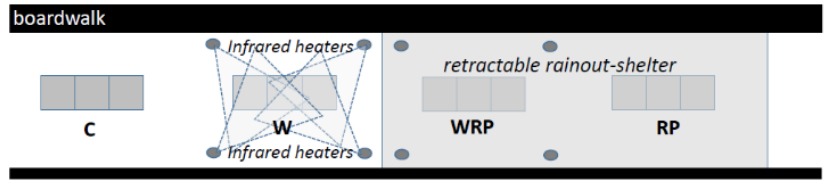

Fig. 1. Scheme of the WETMAN climate manipulation site (C-control, W - warming, WRP- warming and reduction of precipitation, $\mathrm{RP}$ - reduction of precipitation).

The site is under manipulation since 2014 under the WETMAN climate manipulation experiment $[23,24]$. The experimental site is located on $70 \mathrm{~cm}$ thick floating peat carpet, with dominance of Sphagnum spp., Carex rostrata, Oxycoccus palustris (together it makes around $90 \%$ of vegetation), among other Carex limosa, Eriophorum angustifolium, Menyanthes trifoliate etc. can be seen in treatment sites. The temperature was increased by continuous use of infrared heaters $(400 \mathrm{~W}$ $\mathrm{x} 4$ per site), whereas night time precipitation was reduced by using automatic retractable curtain $[23,24]$.

\subsection{Top of Canopy Reflectance measurement and Vls calculation}

In August 2017 two field campaigns were carried out under the clear sky condition to collect the data presented in this study. The Top of Canopy (TOC) reflectance was measured with ASD Handheld-2 spectroradiometer (Malvern Panalytical Ltd., UK), operating in the visible and near-infrared $(375-1075$ $\mathrm{nm})$ spectral range with a full width at half maximum (FWHM) of $3 \mathrm{~nm}$ for the computation of visible to nearinfrared reflectance and vegetation indices. The measurments were performed from a tram moving along the sites above the canopy, in order to not disturb the peatalnd surface. The ASD was held around $70 \mathrm{~cm}$ above the plot surface at nadir position, placed around the middle of each plot. The footprint of the sensor was around $25 \mathrm{~cm}$. Three random measurements around the middle of the plot were performed for the collection of reflectance data. Before each measurement, a baseline measurement was performed by calculating dark current and reflactance from the white reference penel simultaneously. Spectralon white reference panel (Labsphere Inc., U.S.A.) mounted on a levelled tripod was used to estimate incoming radiation at the time of the target measurement. The measurements were performed in between 11:00 to 14:00. The VIs were calculated according to Table 1.

Table 1. Formulae used for VIs calculation.

\begin{tabular}{|c|c|c|}
\hline Indices & Formula & Reference \\
\hline NDVI & $\frac{\rho 850-\rho 670}{\rho 850+\rho 670}$ & {$[25]$} \\
\hline Cigreen & $\frac{\rho 850}{\rho 560}-1$ & {$[26]$} \\
\hline PRI & $\frac{\rho 570-\rho 531}{\rho 570+\rho 531}$ & {$[27]$} \\
\hline WBI & $\frac{\rho 900}{\rho 970}$ & {$[28]$} \\
\hline MTCI & $\frac{\rho 750-\rho 710}{\rho 710+\rho 680}$ & {$[29]$} \\
\hline SR & $\frac{\rho 800}{\rho 680}$ & {$[30]$} \\
\hline NIRv & $N I R t \times N D V I$ & {$[18]$} \\
\hline
\end{tabular}

\subsection{LAI and Chlorophyll content measurement}

The SunScan plant canopy analyzer system (Delta-T Devices Ltd., UK) was used for the purpose to collect LAI measurement. The one meter long LAI wand was placed in parallel to the frame at three different position in plot, and twice it was kept diagonally on plot, for the purpose to calculate LAI, in total five repetitions were performed for each plot. While placing the wand we took care that the wand is balanced and looking vertically upward, whereas it also do not press the vascular plants. 
The SunScan was calibrated with beam fraction sensor, which measures photosynthetic active radiation at the same time when the SunScan wand takes measurements, whereas CCM 300 (OPTI-SCIENCES, USA) was used to measure the chlorophyll content of the individual plant and then multiplied with the abundance of different plant species (data not shown here) to calculate the total chlorophyll content of the plot. Three random plants of a plant species were selected from the plot and chlorophyll content was measured from the middle of the leaf. Few Sphagnum spp. was taken together to cover the CCM sensor. An average was taken from the two days data of three plots, and multiplied with plant abundance, to reach the species-specific chlorophyll content value for each plot. Four major species (Carex rostrate, Oxycoccus palustris, Menyanthes trifoliate, and Sphagnum sp., which were responsible for almost $90 \%$ of total vegetation) were measured for the purpose of chlorophyll content measurement.

\subsection{Statistical analysis}

All the data were analysed according to the experimental design, using Origin and $\mathrm{R}$ software. The means of each trait were compared to control according to the Duncan multiple range test at $p \leq 0.05$. One way ANOVA and Pearson's correlation coefficient were performed to represent the data. Pearson's correlation matrix was to observe any correlations among different variables. The matrix was drawn in accordance to the method described by Pearson [31]. The diagonal elements (correlations of variables with themselves) are always equal to unity. The correlation factors are always in between -1 to +1 ( 0 : no correlation and \pm 1 : high correlation). A positive or negative value indicates that the two correlated parameters increase (or decrease) simultaneously.

\section{Result and discussion}

\subsection{Impact of environmental manipulation on sites}

The treatment resulted from 0.7 to $1.2{ }^{\circ} \mathrm{C}$ increase in average peat day temperature at $2 \mathrm{~cm}$ depth, for August 2017, whereas around $32 \%$ decrease in precipitation was observed till the end of August 2017 (Table 2).

Table 2. Impact of manipulation on temperature and precipitation.

\begin{tabular}{|c|c|c|c|c|}
\hline Conditions & C & W & WRP & RP \\
\hline $\begin{array}{c}\text { Temperature } \\
\left({ }^{\circ} \mathrm{C}\right)\end{array}$ & 17.4 & 18.3 & 18.6 & 18.1 \\
\hline $\begin{array}{c}\text { Precipitation* } \\
(* \text { till end of } \\
\text { August) }\end{array}$ & \multicolumn{2}{|c|}{$644 \mathrm{~mm}$} & \multicolumn{2}{|c|}{$438 \mathrm{~mm}$} \\
\hline
\end{tabular}

\subsection{Impact of environmental manipulation on VIs, LAI, and chlorophyll content}

Different VIs were analyzed in order to show the overall impact of climate manipulation on the peatland vegetation. The scattered plot drown in Figure 2 clearly shows a deviation in different VIs, LAI and chlorophyll content in between different treatment. NDVI, SR, NIRv, CIgreen, MTCI, and chlorophyll content was observed to be significantly reduced whereas, PRI and LAI was observed to be significantly increased under W and WRP conditions. WBI was observed to behave in an unexpected way and was the highest in WRP site. One way ANOVA shows that at the 0.05 level, the means for each VIs, LAI, and chlorophyll content were significantly different.

Different plant communities may reflect the solar radiation in different ways, especially reflectance in short wave infra-red regions of spectrum is lower in Sphagnum than for vascular plants $[32,33]$. Therefore, it is more difficult to interpret the result when the proportion of plant changes with manipulation, which is the case in this study.
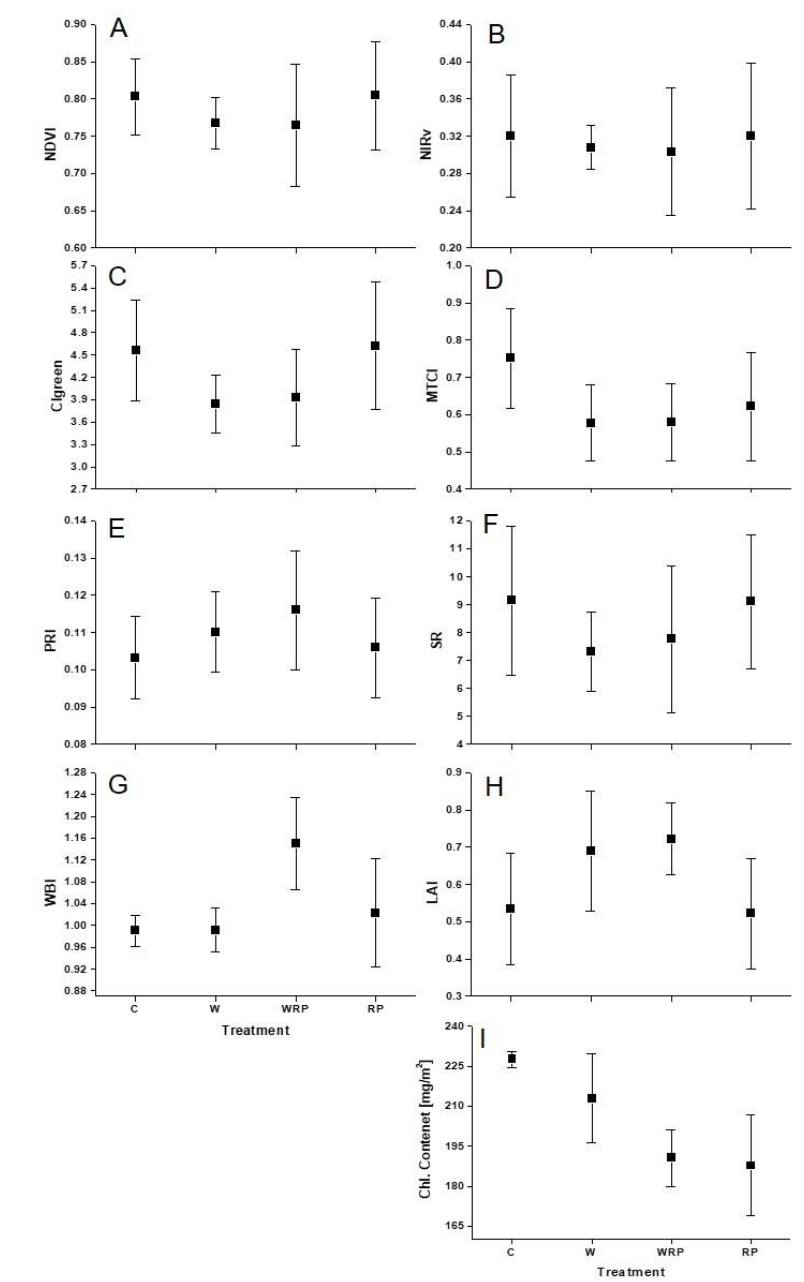

Fig. 2. Impact of environmental manipulation on different VIs (A-G), LAI (H), and chlorophyll content (I). 
An increase in vascular plants are known to increase photosynthesis, autotropic and heterotrophic respiration [34]. Several studies have shown a good linear correlation in between NDVI and gross primary production (GPP), whereas with an increase in NDVI, the GPP increases [35]. Estimation of GPP is one of the methods to evaluate photosynthesis. Thus it could be speculated that, with an increase in vascular plants the NDVI should increase, but it is exactly opposite to what was observed. The reason behind that in Sphagnum dominated peatland the decrease in NDVI due to drying
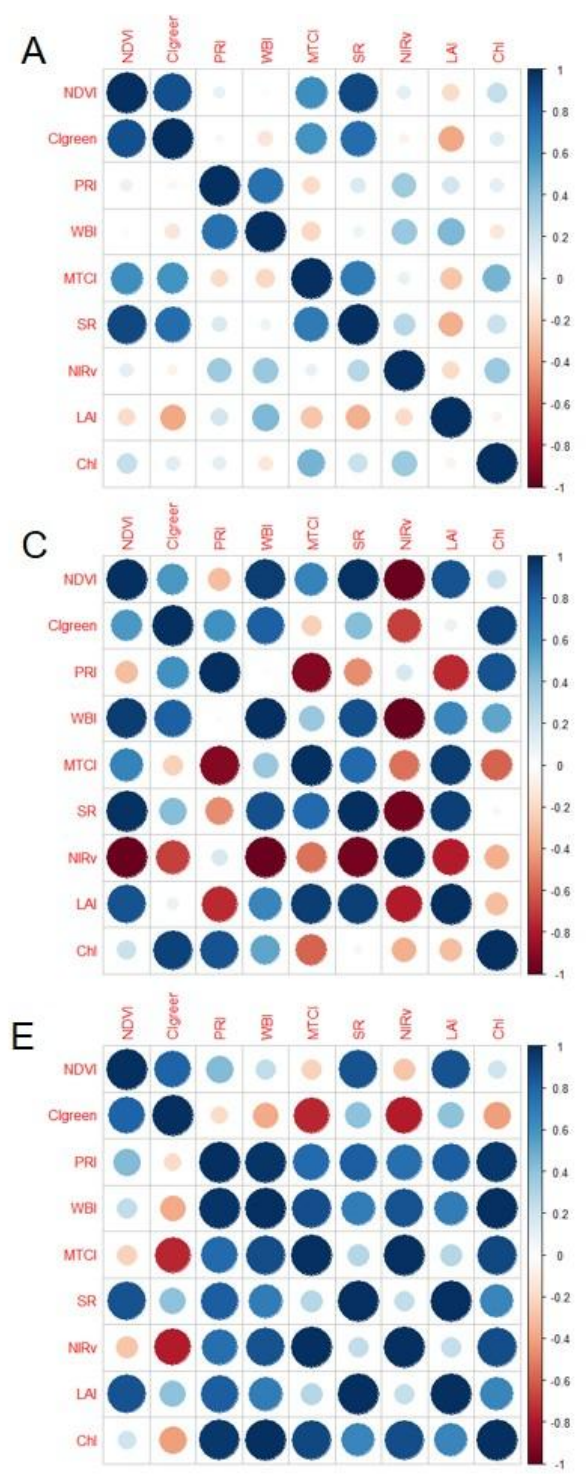

of Sphagnum in W and WRP conditions was dominated by any increasing impact of vascular plants on NDVI (considering its lower contribution in total vegetation). Similar conclusion can be reached through observing SR and NIRv (Fig. 2). Recently NIRv has been shown to be proxy for plant fluorescence, and thus in better correlation with GPP [18]. In this study we observe the similar pattern in between NDVI and NIRv under different treatment conditions; this can be due to small number of data analyzed for this study, which may change when the data for longer period is analyzed.

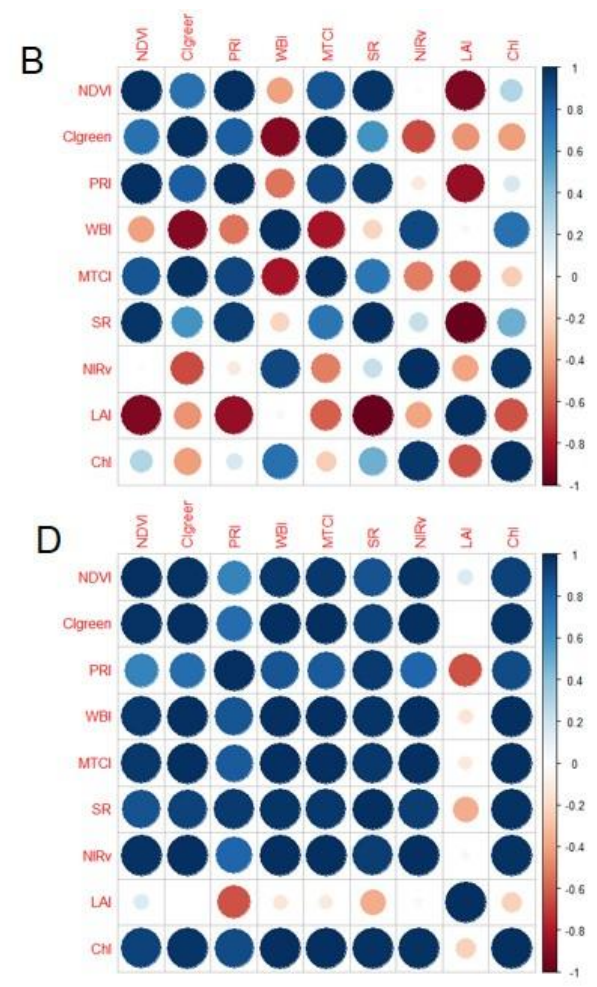

Fig. 3. The impact of environment manipulation on the realtionship of different variables, shown by Pearson's correlation coefficient. " $\mathrm{A}$ " is showing cumulative realtionship when all treatment was considered, whereas "B-E" is showing the relationship under $\mathrm{C}, \mathrm{W}$, WRP, and RP treatment, respectively.

MTCI was observed to better represent the impact of treatment on chlorophyll in comparison to CIgreen when compared with chlorophyll content measurement at leaf level. Few reports have shown that beyond $740 \mathrm{~nm}$ the index may lose its sensitivity to chlorophyll content [36], especially in water saturated ecosystem like peatland [33] due to which the MTCI may best represent the changes in chlorophyll in comparison to CIgreen. In peatland ecosystem the level of water table plays a crucial role for its vegetation, even a slight drop in water table may impact the vegetation drastically. Here we observed a significantly higher WBI, under WRP treatment (Figure 2G), which is in opposite to our expectation of lower WBI, due to more dry condition in WRP. In laboratory condition a linear relationship between WBI and Sphagnum water content has been 
observed [37], but in nature, several factors influence the radiations such as humidity, water depth, difference in composition of vegetation, canopy structure etc., which may be the reason for unexpected response of WBI to WRP treatment, and is subject to further study. An increase in LAI under $\mathrm{W}$ and WRP condition indicates an increase in biomass of vascular plants (Fig. 2H). The peatland under study contains different species of plants with different heights, which makes it difficult to measure LAI, especially when there is vertical heterogeneity in vegetation [38]. A measureable increase in vascular plant abundance was observed in $\mathrm{W}$ and WRP treatment sites.

For better understanding of the relationship between different parameters a Pearson's correlation coefficient matrix for different VIs, LAI, and chlorophyll concentration was drawn (Figure 3). When all treatment were considered together NDVI was observed to be in good correlation with SR, CIgreen, and MTCI, whereas, PRI was observed to be in good correlation with WBI and NIRv (Figure 3A). Chlorophyll content observed through plants were observed to be in good correlation with NDVI, MTCI, SR, and NIRv (Figure 3A). The correlations between variables were observed to be changed when studied at treatment level (Figure 3B-E). The highest positive correlations between different factors were observed under WRP treatment, where except LAI all other factors were positively correlated with each other. The correlations between different variables were also good under RP treatment, where except CIgreen and NDVI all other factors were observed to be positively correlated. The chlorophyll content measurement at plant level was a direct measurement in comparions to CIgreen and MTCI, therefore, considered more accurate than indices. It was observed that under RP and WRP treatment the MTCI was positively related to chlorophyll content whereas under $\mathrm{C}$ and $\mathrm{W}$ treatment the relationship was negative, whereas chlorophyll content was positively correlated with CIgreen under W and WRP treatment and negative under C and RP. Several studies have shown that the measurement from MTCI and CIgreen can be negatively related [39]. In wheat canopy CIgreen was observed to be highly related to leaf chlorophyll content in comparison to MTCI [40]. Our observation shows it differs for peatlands under different treatment, thus the observation depends on several factors, and especially vegetation types are influencing the measurement a lot $[33,41]$. The low reflectance by Sphagnum in short infrared radiation, may change the calculation with different proportion of vegetation, thus vegetation study is crucial for peatland to well interpret the reflectance signals. The high correlation between different factors under RP conditions indicates the dependency of peatland towards the precipitation, as precipitation is one of the crucial factor regulating ground water level and providing nutrients to the plant on peatland. The warming and reduced precipitation appears to be good for vascular plants whereas, it is stress for Sphagnum, when combined, it impacts different variables in coherent way. Thus increase or decrease of one variable influence the other variables under WRP treatment condition in peatland.

\section{Conclusion}

From the above results we observed that, in an ecosystem like peatland, where the precipitation and changing environment influence a lot the ecosystem, different VIs behave differently. This makes the need of long time study necessary for the purpose to identify a pattern in VIs under different treatment condition. This study gives an idea that VIs such as NIRv can be important in analyzing the photosynthetic processes in the ecosystem like peatland, whereas with changing environment MTCI can better predict the chlorophyll content. There is still a need to understand the abnormal behavior of WBI in WRP condition. The accurate measurement of vegetation will also help to understand the behavior of the VIs. Thus this work shows the challenges and its possible solution for the accurate assesment of enivronmental variation in peatland.

The Research was co-founded by the National Science Centre of Poland within the OPUS project: Sun Induced florescence and photosynthesis of peatland vegetation response to stress caused by water deficits and increased temperature under conditions of climate manipulation experiment (No. 72016/21/B/ST10/02271) and the Polish National Centre for Research and Development within the Polish-Norwegian Research Programme within the WETMAN project (Central European Wetland Ecosystem Feedbacks to Changing Climate - Field Scale Manipulation, Pol-

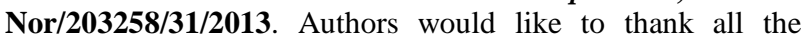
WETMAN team members who worked on the station and helped to develop and maintain the WETMAN site climate manipulation infrastructure, especially to Janusz Olejnik, Jacek Leśny, Marek Urbaniak, Bogdan Chojnicki, Damian Józefczyk, Mateusz Samson, Mariusz Lamentowicz, Dominika Łuców, Anna Basińska, Monika Reczuga.

\section{References}

1. J. Cook, D. Nuccitelli, S.A. Green, M. Richardson, B. Winkler, R. Painting, R. Way, P. Jacobs, A. Skuce, Environ. Res. Lett. 8, 024024 (2013)

2. W.R.L. Anderegg, J.W. Prall, J. Harold, S.H. Schneider, PNAS 107, 12107 (2010)

3. H.F. Jungkunst, A. Bargsten, M. Timme, S. Glatzel, J. Plant Nutr. Soil Sci. 175, 739 (2012)

4. C.M. Dieleman, B.A. Branfireun, J.W. McLaughlin, Z. Lindo, Glob. Chang Biol. 21, 388 (2015)

5. L.Y. Leng, O.H. Ahmed, M.B. Jalloh, Geoscience Frontiers (2018) (article in press)

6. Q. Cui, C. Song, X. Wang, F. Shi, X. Yu, W. Tan, Sci. Total Environ. 616-617, 427 (2018)

7. M. Migliavacca, O. Perez-Priego, M. Rossini, T.S. El-Madany, G. Moreno, C.v.d. Tol, U. Rascher, A. Berninger, V. Bessenbacher, A. Burkart, A. Carrara, F. Fava, J.H. Guan, T.W. Hammer, K. Henkel, E. Juarez-Alcalde, T. Julitta, O. Kolle, 
M.P. Martín, T. Musavi, J. Pacheco-Labrador, A. Pérez-Burgueño, T. Wutzler, S. Zaehle, M. Reichstein, New Phytol. 214, 1078 (2017)

8. B.J.M. Robroek, M.G.C. Schouten, J. Limpens, F. Berendse, H. Poorter, Global Change Biol. 15, 680 (2009)

9. B.N. Sulman, A.R. Desai, N.Z. Saliendra, P.M. Lafleur, L.B. Flanagan, O. Sonnentag, D.S. Mackay, A.G. Barr, G.v.d. Kamp, Geophys. Res. Lett. 37, L19702 (2010)

10. P. McVeigh, M. Sottocornola, N. Foley, P. Leahy, G. Kiely, Agric. Forest Meteorol. 194, 8 (2014)

11. M. Warren, S. Frolking, Z. Dai, S. Kurnianto, Mitig. Adapt. Strat. G1. 22, 1041 (2017)

12. A.R. Cobb, A.M. Hoyt, L. Gandois, J. Eri, R. Dommain, K.A. Salim, M.K. Fuu, N.S.H. Suut, C.F. Harvey, PANAS 114, E5187 (2017)

13. J. Xue, B. Su, J. of Sensors 2017, 1353691 (2017)

14. W. Liu, Z. Zhang, S. Wan, Glob. Chang. Biol. 15, 184 (2009)

15. L. Zhang, Z. Zhou, G. Zhang, Y. Meng, B. Chen, Y. Wang, Eur. J. Agron. 41, 103 (2012)

16. A. Karnieli, N. Agam, R.T. Pinker, M. Anderson, M.L. Imhoff, G.G. Gutman, N. Panov, A. Goldberg, J. Clim. 23, 618 (2009)

17. A.L. Nguy-Robertson, Y. Peng, A.A. Gitelson, T.J. Arkebauer, A. Pimstein, Agricult. Forest Meterol. 192, 140 (2014)

18. G. Badgley, C.B. Field, J.A. Berry, Sci. Advances 3, e1602244 (2017)

19. H.C. Claudio, Y. Cheng, D.A. Fuentes, J.A. Gamon, H. Luo, W. Oechel, H-L. Qiu, A.F. Rahman, D.A. Sims, Remote Sens. Environ. 103, 304 (2006)

20. M. Acosta, R. Juszczak, B. Chojnicki, M. Pavelka, K. Havránková, J. Leśny, L. Krupková, M. Urbaniak, K. Machačová, J. Olejnik, Wetlands 37, 423 (2017)

21. R. Juszczak, M. Acosta, J. Olejnik, Pol. J. Environ. Stud. 21, 643 (2012)

22. K. Milecka, G. Kowalewski, B. Fiałkiewicz-Kozieł, M. Gałka, M. Lamentowicz, B.H. Chojnicki, T. Goslar, J. Barabach, The Holocene 2016, 1-14 (2016)

23. R. Juszczak, A. Basinska, B. Chojnicki, M. Gabka, M. Hoffmann, D. Józefczyk, M. Lamentowicz, J. Leśny, D. Luców, C. Moni, M. Reczuga, M. Samson, H. Silvennoinen, M. Strózecki, M. Urbaniak, M. Zielinska, J. Olejnik, Geophysical Research Abstracts 19, EGU2017-18838-1 (2017)

24. A. Rastogi, M. Stróżecki, A. Basinska, D. Łuców, M. Lamentowicz, M. Gąbka, H.M. Kalaji, B. Chojnicki, J. Leśny, M. Samson, D. Józefczyk, M. Urbaniak, J. Olejnik, H. Silvennoinen, R. Juszczak, Geophysical Research Abstracts 20, EGU2018-13685-1 (2018)

25. J.W. Rouse, R.H. Haas, R.H. Jr., J.A. Schell, J. D.W. Deering, Third ERTS-1 Symposium, Washington, DC: NASA 309 (1974)
26. A.A. Gitelson, S.B. Verma, A. Viña, D.C. Rundquist, G. Keydan, B. Leavitt, T.J. Arkebauer, G.G. Burba, A.E. Suyker, Geophys. Res. Lett. 30, 486 (2003)

27. J. Gamon, J. Penuelas, C. Field, Remote Sens. Environ. 41, 35 (1992)

28. J. Penuelas, J. Pinol, R. Ogaya, I. Filella, Int. J. Remote Sensing. 18, 2869 (1997)

29. J. Dash, P.J. Curran, J. Remote Sensing 25, 5403 (2004)

30. C.F. Jordan, Ecology 50, 663 (1969)

31. A.W. Pearson, Technovation 10, 185 (1990)

32. R.G. Bryant, A.J. Baird, Geophys. Res. Lett. 30, 1134 (2003)

33. K.J. Lees, T. Quaife, R.R.E. Artz, M. Khomik, J.M. Clark, Sci. Total Environ. 615, 857 (2018)

34. J.J. Walker, K.M. de Beurs, R.H. Wynne, Remote Sens. Environ. 144, 85 (2014)

35. Y. Gu, B.K. Wylie, N.B. Bliss, Ecol. Indic. 24, 31 (2013)

36. J.G.P.W. Clevers, L. Kooistra, Proc. ESA Living Planet Symposium 2013, SP-722 (2013)

37. K.E.V. Gaalen, L.B. Flanagan, D.R. Peddle, Oecologia. 153, 19 (2007)

38. S. Garrigues, R. Lacaze, F. Baret, J. T. Morisette, M. Weiss, J.E. Nickeson, R. Fernandes, S. Plummer, N.V. Shabanov, R.B. Myneni, Y. Knyazikhin, W. Yang, J. Geophys. Res. Biogeosci. 113, G02028 (2008)

39. A. Viña, A.A. Gitelson, A.L. Nguy-Robertson, Y. Peng, Remote Sens. Environ. 115, 3468 (2011)

40. B. Kong, B. He, H. Yu, Y. Liu, Math. Probl. Eng. 2017, 4787054 (2017)

41. R.G. Bryant, A.J. Baird, Geophys. Res. Lett. 30, 1134 (2003) 